\title{
Exploring the Weight and Health Status of Adults with Down Syndrome
}

\author{
Susan M Havercamp ${ }^{1}$, Marc J. Tassé ${ }^{1}$, Patricia Navas ${ }^{1}$, Betsey A Benson ${ }^{1}$, Dawn Allain², Kandamurugu Manickam ${ }^{2}$ \\ ${ }^{1}$ The Ohio State University Nisonger Center, USA \\ ${ }^{2}$ The Ohio State University College of Medicine, USA \\ Correspondence: Susan M. Havercamp, The Ohio State University Nisonger Center, USA. \\ E-mail: susan.havercamp@osumc.edu
}

Received: April 11, 2017

doi:10.11114/jets.v5i6.2343
Accepted: May 2, 2017 Online Published: May 7, 2017

URL: https://doi.org/10.11114/jets.v5i6.2343

\begin{abstract}
Background: People with developmental disabilities experience worse health than typically developing peers. This health differential is often described in terms of health disparities, which refers to differences caused or exacerbated by social or access issues. Objective: the goal of this study was to compare the weight status and health conditions of adults with Down syndrome to comparison groups of adults with developmental disabilities and adults with no disability. Methods: Information about health risks and health conditions was collected for 291 adults with Down syndrome living in Ohio through an online survey. We compared this data on adults with Down syndrome to state-level data from adults without disabilities (2012 BRFSS) and Ohio data on a random sample of adults with developmental disabilities other than Down syndrome (2012-2013 National Core Indicators). Results: Adults with Down syndrome were 3 times more likely to be overweight or obese than adults without disabilities. Surprisingly, despite having a body mass index in the overweight or obese range, $70 \%$ of adults with Down syndrome reported having eating habits that were good to excellent and less than $6 \%$ of the Down syndrome sample reported having co-occurring diabetes or hypertension. Discussion: Despite high rates of overweight and obesity, few adults with Down syndrome reported having the chronic health conditions associated with excess weight. Further research is needed to understand the health risks of overweight in adults with Down syndrome and the availability of health promotion programs for this population.
\end{abstract}

Keywords: Down syndrome, health, disparities, obesity, disabilities

\section{Introducation}

Down syndrome (DS) occurs in 1 in every 700 births, making it the most frequent genetic condition associated with intellectual disability (Parker et al., 2010). The life expectancy of children born with Down syndrome has increased 400\% from 12 years to greater than 60 years over the last two generations (Bittles, Bower, Hussain, \& Glasson, 2006; Presson et al., 2013). Because of this dramatic lifespan increase, adults with Down syndrome are now confronted with the same health concerns that accompany aging as the general population (Fisher, 2004). Anomalies of the gastrointestinal tract (Korenberg et al., 1994), sleep apnea (Trois et al., 2009), diabetes (Anwar, Walker, \& Frier, 1998; van Allen, Fung, Jurenka, 1999), increased risk of leukemia (Wechsler et al., 2002), and obesity (Rimmer, Yamaki, Lowry, Wang, \& Vogel, 2010; Stancliffe et al., 2012) are other chronic health conditions that have been frequently reported in this population. Overweight and obesity are associated with increased mortality and morbidity and, as such, are the focus of much public health attention. This paper will explore overweight and obesity and related health conditions in adults with Down syndrome as compared to adults with other developmental disabilities and to adults without disabilities in Ohio.

Obesity was recognized as a public health problem in higher-income countries in the 1970s (World Cancer Research Fund, 2007); however, it was not taken seriously until fairly recently. The general public and health professionals alike typically regarded obesity a result of bad habits and weak will - obese patients were simply advised to follow a low-energy diet. Since the 1980s, however, obesity has increasingly been recognized as a disease in itself, and also as a cause of several disorders and diseases (World Cancer Research Fund, 2007). Obesity lowers life expectancy. It is estimated that at 40 years of age, an obese person can expect to live 6 to 7 years less than a person with a healthy weight. The scientific community has accepted that overweight and obesity cause Type 2 diabetes, gallbladder disease, hypertension, respiratory problems, and coronary heart disease (World Cancer Research Fund, 2007). The US Surgeon General (US Department of Health and Human Services. 2001) identified excess weight as a critical national health 
issue that required immediate attention.

Overweight and obesity in adults with Down syndrome and other developmental disabilities (DD) was addressed in several research studies. Unhealthy weight has frequently been reported for men and women with DS (Rubin, Rimmer, Chicoine, Braddock \& McGuire, 1998; Rimmer, Yamaki, Lowry, Wang, \& Vogel, 2010; Bell \& Bhate, 1992; Stancliff, Lakin, Larson, Engler, Bershadsky, Taub, Fortune, \& Ticha, 2011) and other developmental disabilities (Bell \& Bhate, 1992; Yamaki, 2005); but other research reported mixed findings with respect to the incidence of unhealthy weight in adults with developmental disabilities (Bhaumik, Watson, Thorp, Tyrer \& McGrother, 2008; Emerson, 2005 Stancliff, Lakin, Larson, Engler, Bershadsky, Taub, Fortune, \& Ticha, 2011). Rimmer and Wang (2005) found that, compared to adults without disabilities, adults with DS were twice as likely to be overweight and that extreme obesity $(\mathrm{BMI} \geq 40)$ was four times higher in adults with DS and 2.5 times higher in a sample of adults with DD other than DS. One study found that adolescents with Down syndrome were two to three times more likely to be obese than adolescents in the general population (Rimmer, Yamaki, Lowry, Wang, \& Vogel, 2010). This study also found that secondary health conditions were higher in obese versus healthy weight adolescents with DD including high blood pressure, high blood cholesterol, diabetes, preoccupations with weight, and early maturation. Yamaki (2005) examined the prevalence of obese, overweight, and healthy weight adults with intellectual disability over a five-year period. He found that adults with intellectual disability had a higher prevalence of obesity compared to the general population and that that the obesity prevalence increased over time.

Weight status is determined by two factors: diet and physical activity. Measuring dietary intake typically relies on information provided by the subjects themselves including food records and 24-hour recalls of eating and drinking. These methods depend on the memory, cooperation, and communication ability of the subject, which presents a challenge for adults with DD. For this reason, little is known about the dietary habits of adults with DD. Adolfsson and colleagues (2008) directly observed the eating and physical activity behaviors of a small sample of adults with DD living in the community. They found that $26 \%$ of the energy intake came from between-meal snacking and that intake of fruits, vegetables, and dietary fiber was generally low. Adolfsson et al. (2008) also observed low levels of physical activity. In a study of nutritional status in young adults with DS, Soler and Graupera (2011) found high rates of overweight and obesity; however, metabolic-nutritional and lipid risk factors for type 2 diabetes and cardiovascular disease were within a healthy range.

Understanding the relationships between specific genetic conditions such as DS and associated health needs (e.g., congenital cardiac abnormalities, hypothyroidism, and obesity) is important for the effective provision of health care. In addition, health promotion could prevent or lessen the impact of many of these health conditions (e.g., obesity) if appropriate and accessible intervention is provided. This study contributes to the literature by exploring health risk behavior, including physical activity and overweight/obesity, and obesity-related health conditions in adults with DS. Previous research has identified obesity as a concern for adults with DD and with DS. This study adds to what is known about the health of this population by comparing DS data to a state sample of adults with DD of other etiologies and to adults without disability. This comparison furthers our understanding of the unique health risks and associated chronic health problems of adults with DS.

\subsection{Hypotheses}

The aim of this paper is to compare the weight status and chronic health conditions of adults with Down syndrome to adults with DD of other etiologies and to adults without disabilities.

\section{Method}

\subsection{Participants}

Data about weight status and chronic health conditions of Ohioans with DS were compared to population estimates from existing datasets for adults with DD receiving developmental disability services in the State of Ohio and with data from Ohioans without disabilities. A total of 291 adults with DS, 370 adults with DD, and 9,176 adults without disabilities were identified from three different sources (an on-line Down syndrome health survey, 2012-2013 Ohio National Core Indicators (NCI), and the Ohio Behavior Risk Factor Surveillance Survey (BRFSS; Center for Disease Control and Prevention, 2012, respectively).

\subsubsection{Adults with Down Syndrome}

A total of 291 adults with DS were recruited to participate in an online health survey. Inclusion criteria for this survey included being 18 years of age or older, having Down syndrome, and living in the state of Ohio. Surveys could be completed by adults with DS or a caregiver who knew an adults with DS well. Guardianship status was neither an exclusion nor inclusion criteria as completion of the online survey implied consent. 


\subsubsection{Adults with Developmental Disabilities (Excluding Down Syndrome)}

Population estimates for Ohioans with DD (excluding Down syndrome) were obtained from the National Core Indicators database. Individuals identified as having DS in the Ohio NCI 2012-2013 database $(\mathrm{N}=48)$ were excluded from the NCI "developmental disability" (DD) sample to avoid data conflation with the Down syndrome sample. The remaining DD sample included 370 adults receiving developmental disability services in Ohio.

\subsubsection{Adults without Disabilities}

Population based estimates for Ohioans without disabilities (No Disability group) were drawn from the 2012 Ohio Behavior Risk Factor Surveillance Survey (BRFSS). Adults were included in the No Disability group if they answered negatively to the following two questions: (a) "Are you limited in any way in any activities because of physical, mental, or emotional problems?" and (b) "Do you now have any health problem that requires you to use special equipment, such as a cane, a wheelchair, a special bed, or a special telephone?". The No Disability group was comprised of 9,176 adults.

\subsection{Measures}

\subsubsection{Down Syndrome Health Survey}

Information about health characteristics of adults with DS living in Ohio was obtained through an on-line health survey. Health information was collected between July 2011 and May 2013. The survey included questions addressing: (a) health behaviors including physical activity and diet; (b) current physical and mental health problems; and (c) weight status. The survey questions were written in such a manner as to allow us to compare the responses from our anonymous DS sample to a larger state sample of adults with DD (i.e., drawn from the Ohio National Core Indicators) as well as adults without disabilities (i.e., drawn from the Behavior Risk Factor Surveillance Survey). See Table 1 for an item comparison.

All data collected were anonymous, with no personal health information identifiers attached. Completion of the online health questionnaire implied consent.

Table 1. Health Indicators for Down Syndrome Health Survey, National Core Indicators, and Behavior Risk Factor Surveillance Survey

\begin{tabular}{|c|c|c|c|}
\hline Indicator & DS Health Survey & 2012-2013 NCI & 2012 BRFSS \\
\hline \multirow[t]{2}{*}{ Body Mass Index } & Height & Height & Height \\
\hline & Weight & Weight & Weight \\
\hline \multirow[t]{3}{*}{ Physical activity } & $\begin{array}{l}\text { Does this person routinely } \\
\text { engage in any moderate } \\
\text { physical activity } \\
\text { (moderate } \\
\text { activity that causes some } \\
\text { increase in breathing or } \\
\text { heart rate)? }\end{array}$ & $\begin{array}{l}\text { Does this person } \\
\text { routinely engage in } \\
\text { moderate physical } \\
\text { activity? }\end{array}$ & $\begin{array}{l}\text { - } 2013 \text { BRFSS- } \\
\text { During the past month, other than } \\
\text { your regular job, did you } \\
\text { participate in any physical } \\
\text { activities or exercise such as } \\
\text { running, calisthenics, golf, } \\
\text { gardening, or walking for } \\
\text { exercise? }\end{array}$ \\
\hline & $\begin{array}{l}\text { If yes, does the moderate } \\
\text { physical activity last } 30 \\
\text { minutes or more? }\end{array}$ & $\begin{array}{l}\text { Does the moderate } \\
\text { physical activity last } \\
30 \text { minutes or more? }\end{array}$ & $\begin{array}{l}\text { When you took part in this } \\
\text { activity, for how many minutes or } \\
\text { hours did you usually keep at it? }\end{array}$ \\
\hline & $\begin{array}{l}\text { If yes, how many times } \\
\text { per week? }\end{array}$ & $\begin{array}{l}\text { If yes, how many } \\
\text { times per week? }\end{array}$ & $\begin{array}{l}\text { How many times per week or } \\
\text { month did you take part in this } \\
\text { activity? }\end{array}$ \\
\hline Nutrition & $\begin{array}{l}\text { Eating habits in general } \\
\text { compared to other people } \\
\text { the same age without } \\
\text { intellectual disability }\end{array}$ & No indicator & No indictor \\
\hline
\end{tabular}

\subsubsection{Ohio National Core Indicators}

Healthcare data of adults with DD living in Ohio were obtained using the National Core Indicators (NCI)

2012-2013 Consumer Survey. The NCI includes approximately 150 consumer, family, system, and health and safety outcome indicators that measure the performance of DD services across States (National Core Indicators, 2012). Both 
face-to-face interview with the person receiving services and proxy respondents were conducted, and demographic and health service information was provided from the case file. Sample selection was randomized and limited to those individuals receiving at least one service from the state department of developmental disability. Although there could be imperfect agreement between individuals with DD and proxy respondents (Lunsky, Emery, \& Benson, 2002), good inter-rater agreement and test-retest reliability has been reported (National Core Indicators, 2012; Smith \& Ashbaugh, 2001).

\subsubsection{Behavior Risk Factor Surveillance Survey}

Information about health of adults without disabilities living in Ohio was drawn from 2012 Behavior Risk Factor Surveillance Survey (BRFSS) data. The BRFSS is a state-based system of telephone health surveys, providing timely and accurate data on health risk behaviors, preventive health practices, and healthcare access primarily related to chronic disease and injury for the adult population (aged 18 and older) living in households (Center for Disease Control and Prevention, 2012). Data were collected from a randomly selected adult in a household using landline or cellular telephone. Most questions on the core BRFSS questionnaire have been reported as at least moderately reliable and valid, with many of them being highly reliable and valid (Nelson, Holtzman, Bolen, Stanwyck, \& Mack, 2000).

The 2012 BRFSS included disability identifier questions. Disability was identified by an affirmative response to either of the following questions: (a) "Are you limited in any way in any activities because of physical, mental, or emotional problems?" or (b) "Do you now have any health problem that requires you to use special equipment, such as a cane, a wheelchair, a special bed, or a special telephone?".

The BRFSS survey methodology probably does not reach people with developmental disabilities because these adults may not respond to telephone surveys and, if they did respond, they may not admit to having a disability because of the stigma associated with developmental disabilities (Havercamp et al., 2004). In addition, BRFSS selects individuals 18 years of age or older living in households thereby excluding institutionalized populations and people living in congregate settings (Krahn, Fox, Campbell, Ramon, \& Jesien, 2010).

\subsection{Procedure}

Participants with DS were contacted through various disability organizations and service-providers established in Ohio such as the Down syndrome Association of Central Ohio (DSACO), Down Syndrome Achieves, or the Franklin County Board of Developmental Disabilities Support Service Administrators. Information was also disseminated through the aforementioned association/organization and other Down syndrome groups' newsletters, listserv announcements, blogs, websites, conference announcements, and the patient roster of The Ohio State University Wexner Medical Center Down Syndrome Clinic. This recruitment information provided a URL Link to the Survey Monkey-hosted health questionnaire. Participants received incentives that were congruent with the time commitment for the study (i.e., a $\$ 5.00$ gift card from a sporting goods store and an opportunity to be entered into a drawing to win one of three combination Wii + Wii Fit systems).

BRFSS 2012 data and other comprehensive documentation (i.e., codebooks, design documents, and methodology) were obtained from the BRFSS Annual Survey Data section of the CDC Website (Center for Disease Control and Prevention, 2012). Ohio NCI 2012-2013 data was provided by the Ohio Department of Developmental Disabilities. We sought and obtained all appropriate approvals from The Ohio State University Human Subjects Institutional Review Board.

\section{Results}

Chi-square tests were used to assess differences in categorical variables. Means and standard deviations were computed for continuous variables. Differences in continuous variables (i.e., age) were examined using a Kruskal-Wallis analysis when deviations from normality were detected. Binary logistic regression analysis was conducted to examine the effects of different risk factors that could contribute to overweight or obesity. We report on obesity, physical activity, and health conditions associated with obesity in three samples: adults with DS, adults with DD, and adults without disabilities. For these analyses, age groups (i.e., 18-24; 25-34; 35-44; 45-54; 54-64; >64) were combined (i.e., 18-34; 35-54; >54) to ensure that expected frequencies in each cell were greater than 1 and no more than $20 \%$ were less than 5 (e.g., only two individuals with DS were aged 65 and older).

The sample of adults with DS was comprised of 154 (52.9\%) men and 137 (47.1\%) women. The analysis of the Pearson standardized residuals showed that the proportions of men and women by different age groups (i.e., 18-24; 25-34; 35-44; $45-54 ; 55-64 ;+65)$ were equiprobable: $\chi^{2}(5, \mathrm{~N}=291)=6.511, p=.26$. The age of the adults with DS ranged from 18 to 79 years old $(M=33.71, S D=12.47)$. As expected, due to the lower life expectancy of individuals with DS, age distribution was right-skewed with skewness of .782 ( $\mathrm{SE}=.143)($ see Table 2).

Most cases of Down syndrome (74\%) were reported to result from trisomy 21. Approximatelu four percent $(\mathrm{N}=11)$ reported a chromosomal translocation, $2.1 \%$ mosaicism, and the remaining $20 \%(\mathrm{~N}=58)$ did not know the chromosomal 
cause for the diagnosis of Down syndrome. These rates are very similar to those previously reported (Chapman \& Hesketh, 2000). Most participants with DS presented mild (20.3\%) or moderate (64.9\%) levels of intellectual disability, while $12.4 \%$ had severe/profound intellectual disability. Six participants did not know their level of intellectual disability, and data was missing for one case. No significant association was found between gender and level of intellectual disability. Compared to those with DD due to other etiologies, the odds for those with DS to present moderate intellectual disability were 3.957, $p<.001,95 \%$ CI [2.858, 5.478]. As reported in other studies (Stancliffe et al., 2012), a large majority (71.5\%) of adults with Down syndrome were living in their parent's or other relative's home. The health survey was completed, in most cases (70\%), by a parent of the adult with Down syndrome, and the adult with DS completed the survey independently in $6.5 \%(\mathrm{~N}=19)$ of the cases. The remaining surveys were completed by a direct-support staff or other adult caregiver.

The DD sample included 370 adults, 199 of whom were male (53.8\%). Participant ages ranged from 18 to 96 , with an average of 43.3 years. Approximately half of the sample (50.5\%) was reported to be independent of guardianship and most were single, never married (94.3\%). Level of intellectual disability was reported to be mild $(42.2 \%)$, moderate $(31.9 \%)$, severe $(12.7 \%)$, profound $(10.3 \%)$, and unspecified $(1.6 \%)$. The individual's mobility was described as independent without aids (70.3\%), uses aids or wheelchair independently (19.2\%), and non-ambulatory needs assistance $(10.5 \%)$.

The No Disability group was comprised of 9,176 adults with an average age of 53.4 years. This sample included more women than men $(59.1 \%)$.

Table 2. Demographics for adults with Down Syndrome, adults with other developmental disabilities, and adults without disabilities

\begin{tabular}{c|ccc}
\hline Demographics & Down Syndrome & DD & No Disability \\
\hline Mean Age (years) & 33.7 & 42.5 & 53.4 \\
(SD) & 12.5 & 14.2 & 17.2 \\
Gender (\%) & & & \\
Men & 52.9 & 53.8 & 40.9 \\
Women & 47.1 & 46.2 & 59.1 \\
& & & \\
Intellectual Disability & & & \\
Severity (\%) & & & - \\
None & 0 & 0 & - \\
Mild & 20,3 & 42.2 & - \\
Moderate & 64.9 & 31.9 & - \\
Severe & 11.7 & 12.7 & $100 \%$ \\
Profound & 0.7 & 10.3 & \\
Unknown & 2.4 & 3.0 & \\
\hline
\end{tabular}

\subsection{Comparisions between the Three Samples}

As shown in Table 2 and consistent with previous findings (Esbensen, Mailick, \& Krauss, 2008; Shin et al., 2009), a higher proportion of adults with DS were male compared to adults without disabilities ( $52.9 \%$ vs. $40.9 \%$, respectively), $\chi^{2}(1,9,467)=16.815, p<.001$. No differences were found by gender between the groups of DS and DD due to other etiologies $\chi^{2}(1,661)=.049, p=.825$.

Age of participants without disabilities ranged from 18 to 99 years old $(M=53.35, S D=17.24)$. Participants with Down syndrome were significantly younger than adults without disabilities. Thus, the proportion of adults with DS in the 18-24 and 25-34 age groups was significantly higher (29.2\% and 30.9\%, respectively vs. $5.8 \%$ and $11.2 \%$ for those without disabilities) $\chi^{2}(1,9,467)=251.290, p<.001 ; \chi^{2}(1,9,467)=105.565, p<.001$. The number of people without disabilities was significantly higher in the $55-64$ age group $(22.2 \%$ vs. $6.2 \%) \chi^{2}(1,9,467)=42.516, p<.001$. Only 2 individuals with DS were aged 65 and over.

Individuals with DD due to other etiologies were also significantly older than those with DS. Age of the adults with DD ranged from 18 to 97 years $(M=44.06, S D=14.301)$. The proportion of adults with DS in the 18-24 and 25-34 age 
groups was significantly higher $\left(29.6 \%\right.$ and $30.6 \%$, respectively vs. $8.5 \%$ and $20.8 \%$ for those with DD) $\chi^{2}(1,661)=$ $51.773, p<.001 ; \chi^{2}(1,661)=8.273, p<.01$. The number of people with DD was significantly higher than the DS group in the $35-44(23.5 \%$ vs. $16.5 \%), 45-54(22.4 \%$ vs. $15.8 \%)$, and $55-64(18.6 \%$ vs. $6.9 \%)$ age groups: $\chi^{2}(1,661)=$ $4.937, p<.05 ; \chi^{2}(1,661)=4.551, p<.05 ; \chi^{2}(1,661)=19.386, p<.001$.

Similar to adults with DS, a large percentage of adults with DD were living with their parents or relatives (43.8\%); however, they were significantly less likely than adults with DS to be living with their family, $\chi^{2}(1,661)=50.695, p$ $<.001,95 \%$ CI $[.414, .622]$.

\subsection{Overweight and Obesity}

Commensurate with the World Health Organization weight status categories, we classified BMI of 25 through 30 as overweight and BMI greater than or equal to 30 as obese. Table 3 provides a comparison of weight categories across the three samples. More than 3 out of 4 adults with DS were obese (48.5\%) or overweight (28.5\%). Among adults with DD, almost $62 \%$ were either obese $(33.2 \%)$ or overweight $(28.4 \%)$. The obesity rate of adults without disabilities was $25.5 \%$ $(\mathrm{N}=2,342)$. The high rate of obesity in DD is consistent with previous research (Havercamp et al., 2004; Rimmer et al., 2010; Rubin et al., 1998).

As shown in Table 3, Down syndrome was significantly associated with being obese in all the age groups, and this risk increased with age. Thus, adults and older adults with DS had 3 times the odds as adults and older adults without disabilities at being obese (Table 3). Surprisingly, despite having a BMI > 30, a large majority (70\%) of obese adults with DS reported considering their eating habits as good, very good, or excellent.

Table 3. Odds ratio of being overweight or obese by disability and age group

\begin{tabular}{|c|c|c|c|c|c|c|c|c|}
\hline & & \multicolumn{2}{|c|}{ Down Syndrome } & \multicolumn{2}{|c|}{ No Disability } & & & \\
\hline Age & Condition & $\mathrm{N}$ & $\%$ & $\mathrm{~N}$ & $\%$ & OR $(95 \% \mathrm{CI})$ & $\chi^{2}(1)$ & $p$ \\
\hline \multirow[t]{3}{*}{$18-34$} & Normal weight (BMI 18.5 to 24.9 ) & 39 & 22.8 & 668 & 46.5 & $.341[.235, .494]$ & 34.691 & $<.001$ \\
\hline & Overweight (BMI>25) & 58 & 39.9 & 456 & 31.7 & $1.105[.790,1.546]$ & .343 & $>.05$ \\
\hline & Obesity $(\mathrm{BMI}>30)$ & 74 & 43.3 & 314 & 21.8 & $2.731[1.968,3.789]$ & 38.386 & $<.001$ \\
\hline \multirow[t]{3}{*}{$35-54$} & Normal weight (BMI 18.5 to 24.9 ) & 15 & 16.0 & 913 & 32.0 & $.403[.231, .704]$ & 10.897 & $<.001$ \\
\hline & Overweight (BMI>25) & 23 & 24.5 & 1,054 & 37.0 & $.552[.343, .889]$ & 6.143 & $<.05$ \\
\hline & Obesity (BMI>30) & 56 & 59.6 & 883 & 31.0 & $3.283[2.158,4.994]$ & 34.247 & $<.001$ \\
\hline \multirow[t]{3}{*}{$>54$} & Normal weight (BMI 18.5 to 24.9 ) & 8 & 38.1 & 1,046 & 32.1 & $1.961[.811,4.744]$ & 2.316 & $>.05$ \\
\hline & Overweight (BMI>25) & 2 & 9.5 & 1,828 & 41.7 & $.193[.045, .829)]$ & 6.091 & $<.05$ \\
\hline & Obesity (BMI>30) & 11 & 52.4 & 1,145 & 26.1 & $3.388[1.400,8.197]$ & 8.267 & $<.01$ \\
\hline
\end{tabular}

\subsection{Health Behaviors Associated with Overweight/Obesity}

Overweight and obesity status is a function of energy balance (Hill \& Melanson, 1999), that is, the balance between energy expenditure (physical activity) and energy intake (calories). People gain weight if they take in more energy than they use. The US Department of Health and Human Services Office of Disease Prevention and Health Promotion (2008) recommends 30 minutes of moderate physical activity at least 5 times per week.

For this study, we defined moderate physical activity as causing some increase in breathing or heart rate. A majority $(62.9 \%)$ of adults with Down syndrome reported engaging in some moderate physical activity, fewer reported engaging in physical activity for 30 minutes or more $(44.0 \%)$. The frequency of physical activity per week was rated as five times or more $(6.2 \%)$, three to four times $(20.6 \%)$, or one to two times per week $(16.8 \%)$ among adults with Down syndrome.

This level of activity was much higher than the DD group of whom $32.4 \%$ reportedly engaged in moderate physical activity, $21.9 \%$ for 30 minutes or more, and weekly frequency ranging from five times or more (4.1\%), three to four $(8.4 \%)$, and one to two times $(9.5 \%)$. We were unable to compare these rates directly to adults without disabilities because detailed physical activity indicators were not available from the 2012 BRFSS, however, 53.5\% of Ohioans without disabilities reported sufficient physical activity in 2013 where sufficient physical activity was defined as at least 150 minutes of moderate physical activity per week.

\subsection{Chronic Health Conditions}

Eighty-eight percent $(\mathrm{N}=256)$ of the total group of adults with DS who completed our health survey reported at least one secondary health condition. The most commonly reported health conditions were: hypothyroidism (34\%), skin conditions $(33 \%)$, allergies $(24 \%)$, sleep apnea (21\%), and digestive problems (20\%). Other conditions, such as hypertension, were rarely reported $(\mathrm{N}=2$ or $0.7 \%)$. Unfortunately, these conditions were not measured by available population-based surveys (NCI and BRFSS), which prevented prevalence comparisons to population estimates. BRFSS did have indicators for other chronic health conditions such as asthma, respiratory conditions, and arthritis, rheumatism or osteoarthritis. Differences between individuals with DS and adults without disabilities on these conditions are presented in Table 4. 
Table 4. Chronic health conditions in adults with Down syndrome and adults without disabilities

\begin{tabular}{|c|c|c|c|c|c|c|c|c|}
\hline \multirow[t]{3}{*}{ Condition } & \multirow{3}{*}{ Age group } & \multicolumn{2}{|c|}{ Down syndrome } & \multicolumn{2}{|c|}{ No Disability } & \multirow{3}{*}{$\begin{array}{l}\text { OR }(95 \% \text { CI }) \\
\text { DS/ No disability }\end{array}$} & \multirow{3}{*}{$\chi^{2}(1)$} & \multirow{3}{*}{$p$} \\
\hline & & $\mathrm{N}$ & $\%$ & $\mathrm{~N}$ & $\%$ & & & \\
\hline & & & & & & & & \\
\hline \multirow[t]{3}{*}{ Respiratory conditions } & $18-34$ & 7 & 4.0 & 31 & 2.0 & $2.058[.892,4.745]$ & 2.987 & $>.05$ \\
\hline & $35-54$ & 9 & 9.6 & 110 & 3.7 & $2.790[1.368,5.692]$ & 8.659 & $<.01$ \\
\hline & $>54$ & 2 & 9.1 & 324 & 7.1 & $1.312[.305,5.639]$ & .134 & $>.05$ \\
\hline \multirow[t]{3}{*}{ Asthma } & $18-34$ & 11 & 6.3 & 216 & 13.8 & $.418[.223, .783]$ & 7.867 & $<.01$ \\
\hline & $35-54$ & 3 & 3.2 & 308 & 10.2 & $.290[.091, .920]$ & 5.003 & $<.05$ \\
\hline & $>54$ & 0 & 0 & 386 & 8.4 & & & \\
\hline \multirow[t]{3}{*}{ Arthritis, rheumatism or osteoarthritis } & $18-34$ & 4 & 4.0 & 80 & 5.1 & $.771[.350,1.698]$ & .418 & $>.05$ \\
\hline & $35-54$ & 22 & 23.4 & 526 & 17.5 & $1.443[.887,2.347]$ & 2.204 & $>.05$ \\
\hline & $>54$ & 6 & 31.8 & 1,860 & 40.6 & $.683[.278,1.678]$ & .701 & $>.05$ \\
\hline
\end{tabular}

Note: Point estimates for the No Disability groups are weighted. Point estimates for the DS group are not weighted.

As shown in Table 4, DS was associated with risk of respiratory conditions (other than asthma) in the 35-54 age group; although DS carried a lower risk of asthma among 18-34 and 35-54 year olds. This finding was statistically significant for both age groups. None of the individuals with DS aged 54 and older had ever been diagnosed with asthma, whereas $386(8.4 \%)$ of those same age individuals without disabilities $(\mathrm{N}=4,600)$ reported having asthma. Age was strongly associated with the risk of having arthritis, rheumatism or osteoarthritis in individuals without disabilities $\left(\chi^{2}(2,9,152)\right.$ $=948.766, p<.001)$ and with DS $(\chi 2(2, \mathrm{~N}=291)=26.989, p<.001)$, and individuals with DS were as likely as adults without disabilities to present these conditions when risk was analyzed within each age group (Table 4).

Notable trends emerged from certain low incidence conditions, although firm conclusions cannot be drawn. Relatively few adults in our DS sample reported having cancer $(\mathrm{n}=14,4.8 \%)$. This cancer rate was significantly lower than reported in the no disability group $(12.8 \%$; OR $=.345,95 \% \mathrm{CI}[.201, .593], p<.001)$. Also notable was that very few adults with DS had a history of breast or prostate cancer (one and two cases, respectively). In contrast, seven of the fourteen cases of cancer in the DS group (50\%) were reported to be leukemia. It was not possible to compare the cancer type prevalence of adults with DS to adults without disabilities because cancer type was not measured on the 2012 BRFSS; however, the high incidence of leukemia in DS is consistent with previous research (Bittles, Bower, Hussain, \& Glasson, 2007; Goldacre, Wotton, Seagroatt, \& Yeates, 2004).

Although all of the adults with DS who had a diagnosis of diabetes fell in the overweight or obese range $(\mathrm{N}=15)$, the odds of being diagnosed with diabetes were two times greater for adults without disabilities who were overweight or obese $\left(\chi^{2}(1,5,891)=9.263 p<.01 ; \mathrm{OR}=2.228,95 \%\right.$ CI $\left.[1.312,3.782]\right)$ compared to adults with DS.

\subsection{Factors Contributing to Overweight and Obesity in Adults with Developmental Disabilities}

Limiting our analyses to the adults with DD sample (now including the 48 adults with DS previously excluded from this sample), we explored factors contributing to overweight and obesity using a binary logistic regression analysis. Results were adjusted for potential contributing variables such as condition $(1=$ Down syndrome $)$, gender $(1=$ male $)$, group age (recoded into dummy variables with 18-34 years old as the reference group), mobility $(1=$ moves self around environment with aids), other developmental disabilities $(1=$ yes $)$, psychiatric diagnoses $(1=$ yes $)$, engagement in physical activity $(1=$ yes $)$, level of intellectual disability $(1=$ mild, $4=$ profound, with mild ID as the reference category), and living with parents or relatives $(1=$ yes $)$. Table 5 , shows the logistic regression coefficient, Wald test, and odds ratio for each of the predictors. Using a .05 criterion of statistical significance, condition, mobility, psychiatric diagnosis, and physical activity had significant partial effects. The odds ratio for condition indicates that, when holding all other variables constant, adults with DS were 3.4 times more likely to be overweight or obese compared to adults with other types of DD. Although significant, the effect of having a psychiatric diagnosis was smaller, with an odds ratio of 1.6 for adults with a psychiatric diagnosis. Inverted odds ratios for the dummy variables indicate that the odds of being overweight or obese were 1.9 times higher for those with mobility limitations and 1.7 times higher for those that did not engage in regular physical activity. 
Table 5. Logistic regression analysis on overweight or obese status.

\begin{tabular}{|c|c|c|c|c|c|c|c|}
\hline & \multirow[b]{2}{*}{ B } & \multirow[b]{2}{*}{ S.E. } & \multirow[b]{2}{*}{ Wald } & \multirow[b]{2}{*}{$p<$} & \multirow[b]{2}{*}{$\operatorname{Exp}(B)$} & \multicolumn{2}{|c|}{$95 \%$ C.I. } \\
\hline & & & & & & Lower & Upper \\
\hline Down syndrome & 1.216 & .353 & 11.853 & .001 & 3.373 & 1.688 & 6.740 \\
\hline Age group (35-54) & .287 & .281 & 1.041 & .308 & 1.333 & .768 & 2.314 \\
\hline Age group $(+54)$ & -.035 & .324 & .012 & .914 & .966 & .512 & 1.822 \\
\hline Mobility & -.636 & .245 & 6.724 & .010 & .529 & .327 & .856 \\
\hline Other developmental disability & -.017 & .226 & .006 & .940 & .983 & .632 & 1.530 \\
\hline Psychiatric diagnosis & .472 & .217 & 4.747 & .029 & 1.604 & 1.049 & 2.452 \\
\hline Physical activity & -.515 & .202 & 6.514 & .011 & .598 & .402 & .887 \\
\hline Level of ID(moderate) & -.226 & .221 & 1.052 & .305 & .797 & .517 & 1.229 \\
\hline Level of ID (severe) & -.296 & .304 & .946 & .331 & .744 & .410 & 1.350 \\
\hline Level of ID (profound) & -.736 & .392 & 3.527 & .060 & .479 & .222 & 1.033 \\
\hline Living with parents & -.288 & .218 & 1.736 & .188 & .750 & .489 & 1.151 \\
\hline Down syndrome by age (35-54) & .171 & .462 & .137 & .712 & 1.186 & .480 & 2.932 \\
\hline Down syndrome by age $(+54)$ & -.721 & .600 & 1.442 & .230 & .486 & .150 & 1.577 \\
\hline Down syndrome by Gender & -.391 & .307 & 1.622 & .203 & .676 & .370 & 1.235 \\
\hline
\end{tabular}

Note: $R^{2}=.12$ (Nagelkerke). Model $\chi^{2}(15)=52.259 p<.001$.

\section{Discussion}

Overall, 77\% of adults with DS had reported BMIs that were in the overweight or obese range. Overweight and obesity was much higher in adults with DS compared to other adults with DD and among adults without disability, and this risk increased with age. Surprisingly, adults with DS were more likely to engage in physical activity compared to other adults with DD. Despite these very high rates of overweight/obesity, few adults with DS reported diabetes or arterial hypertension. In fact, only 5\% $(\mathrm{n}=16)$ reported having been diagnosed with diabetes and less than $1 \%(\mathrm{n}=2)$ reported having hypertension. Although other studies have reported that diabetes mellitus under the age of 30 years was significantly more common among adults with Down syndrome (Goldacre et al., 2004), only one person younger than 30 years old in our sample had this condition. In fact, among overwiehgt or obese adults, the odds of diabetes were twice as high for adults without disabilities compared to adults with DS.

Adults with DS were highly likely to report secondary health conditions (88\%) and much more likely than adults without disabilities to report respiratory conditions (other than asthma), less likely to report asthma, and equally likely to report arthritis.. DS seemed to reduce the risk of cancer, although the rates of leukemia appeared higher than previous population estimates. Among adults with DD, several factors were identified as increasing risk for overweight including having DS, psychiatric diagnosis, mobility limitations, and sedentary lifestyle. Contrary to results reported by other researchers (Ouellette - Kuntz, 2005; Scheepers et al., 2005), participants in our survey who were living with their parents or relatives did not have significantly higher weight status than individuals living in more structured settings. As noted by other researchers (Havercamp et al., 2004; van Allen et al., 1999) and national and international organizations (Linehan, Walsh, Van Schrojenstein Lantman-de Valk, \& Kerr, 2004; United States Public Health Service, 2002), our findings highlight the real need to focus efforts on better understanding and improving the health of adults with developmental disabilities, and particularly adults with DS.

This study had limitations. First, our Down syndrome sample volunteered to participate in an online survey so these results may not generalize to all adults with Down syndrome. Secondly, information about some sociodemographic variables such as race, socioeconomic status, and rural vs. urban living area, were not available. It is possible that these variables could impact the results of this study as higher rates of obesity has been reported among socertain groups like African Americans and Hispanics with disabilities (Jones \& Sinclair, 2008). Thirdly, not all questionnaires from the Online Survey, BRFSS and NCI were completed in their entirety. Subsequently, the response rates sometimes fluctuated between variables. Finally, although only $6.5 \%(n=19)$ of adults with DS completed the survey themselves, their survey responses may have been biased if they perceived the response as more socially desirable (Adams, Soumerai, Lomas, \& Ross-Degnan, 1999).

Despite these limitations, our large sample $(\mathrm{n}=291)$ and comparison to population-based DD and no disability groups provides some valuable insights into adults with DS and their health risks and health status. Overall, $77 \%$ of adults with DS in our sample had reported BMIs that were in the overweight or obese range. The fact that overweight was not associated with the usual health problems leads us to question the relevance of using BMI indices that are based on general population as a basis of weight status in adults with Down syndrome. Cancer is another area that warrants further exploration. In our sample, fewer than expected adults with DS reported a history of cancer, leukemia being an exception.

Research is needed to improve the measurement of dietary intake and physical activity for people with developmental 
disabilities. Although rapid dietary screeners have been developed to identify people with high fat and low fruit or vegetable intake (Block, Gillespie, Rosenbaum, \& Jenson, 2000), they have not been validated or adapted for adults with developmental disabilities. Physical activity measures, like dietary intake measures, are limited by participant memory and communication ability. Including objective physiological measures of physical fitness, such as volume oxygen max score, would improve our understanding of key health indicators for people with developmental disabilities.

Finally, there is a need to examine the health habits of adults with disabilities and to ensure that health education and health promotion opportunities are accessible to adults with developmental and other disabilities. In addition to expanding public health efforts to be inclusive of people with disabilities, disability service systems must adopt health promotion as a critical aspect of their service. Health is closely tied to quality of life in that healthier people are more active and more engaged in their communities. Disability service providers could have a significant and positive impact on the health and quality of life of people with disabilities by making health promotion a priority.

\section{Acknowledgements}

The authors wish to express our gratitude to the many adults with Down syndrome and their family members who gave their time to contribute to our understanding of health issues for adults with Down syndrome. This study would not have been possible without support from our funders, the Henry E. Coyle Fund of the Columbus Foundation (TFB11-0357 TG) and the U.S. Administration of Intellectual and Developmental Disabilities grant \#99-DD-0621.

\section{References}

Adams, A. S., Soumerai, S. B., Lomas, J., \& Ross-Degnan, D. (1999). Evidence of self-report bias in assessing adherence to guidelines. International Journal for Quality in Health Care, 11(3), 187-192. https://doi.org/10.1093/intqhe/11.3.187

Adolfsson, P., Sydner, Y. M., Fjellström, C., Lewin, B., \& Andersson, A. (2008). Observed dietary intake in adults with intellectual disability living in the community. Food \& Nutrition Research, 52, 1857.

https://doi.org/10.3402/fnr.v52i0.1857

Anwar, A. J., Walker, J. D., \& Frier, B. M. (1998). Type 1 diabetes mellitus and Down's syndrome: prevalence, management and diabetic complications. Diabetic Medicine, 15(2), 160-163. https://doi.org/10.1002/(SICI)1096-9136(199802)15:2<160::AID-DIA537>3.0.CO;2-J

Bhaumik, S., Watson, J. M., Thorp, C. F., Tyrer, F., \& McGrother, C. W. (2008). Body mass index in adults with intellectual disability: distribution, associations and service implications: a population-based prevalence study. Journal of Intellectual Disability Research, 52, 287-298. https://doi.org/10.1111/j.1365-2788.2007.01018

Bittles, A. H., Bower, C., Hussain, R., \& Glasson, E. J. (2006). The four ages of Down syndrome. The European Journal of Public Health, 17(2), 221-225. https://doi.org/10.1093/eurpub/ckl103

Center for Disease Control and Prevention (2012). BRFSS 2012 Survey Data and Documentation. Retrieved from http://www.cdc.gov/brfss/annual_data/annual_2012.html

Chapman, R. S., \& Hesketh, L. J. (2000). Behavioral phenotype of individuals with Down syndrome. Mental Retardation and Developmental Disability Research Reviews, 6(2), 84-95. https://doi.org/10.1002/1098-2779(2000)6:2<84::AID-MRDD2>3.0.CO;2-P

Chicoine, B., McGuire, D., \& Rubin, S. S. (1998). Adults with Down syndrome: Specialty clinic perspectives. In M. P. Janicki \& A. J. Dalton (Eds.), Dementia, aging, and intellectual disabilities: A handbook (pp. 278-93). New York: Brunner/Mazel.

Corbin, S., Holder, M., \& Engstrom, K. (2005). Changing attitudes, changing the world: the health and health care of people with intellectual disabilities. Washington, DC: Special Olympics International.

Drainoni, M., Lee-Hood, C., Tobias, C., Bachman, S. S., Andrew, J., \& Maisels, L. (2006). Cross-disability experiences to health-care access. Journal of Disability Policy Studies, 17(2), 101-115. https://doi.org/10.1177/10442073060170020101

Drum, C., Krahn, G., Peterson, J., Horner-Johnson, W., \& Newton, K. (2009). Health of people with disabilities: Determinants and disparities. In C. Drum, G. Krahn, \& H. Bersani (Eds.), Disabilities and Public Health (pp. 125-144).Washington, D.C: American Public Health Association. https://doi.org/10.2105/9780875531915ch08

Duggan, A., Bradshaw, Y. S., \& Altman, W. (2010). How do I ask about your disability? An examination of interpersonal communication processes between medical students and patients with disabilities. Journal of Health Communication, 15(3), 334-350. https://doi.org/10.1080/10810731003686630

Dykens, E. M. (2007). Psychiatric and behavioral disorders in persons with Down syndrome. Mental Retardation and 
Developmental Disabilities Research Reviews, 13(2), 272-278. https://doi.org/10.1002/mrdd.20159

Emerson, E. (2005), Underweight, obesity and exercise among adults with intellectual disabilities in supported accommodation in Northern England. Journal of Intellectual Disability Research, 49:, 134-143. https://doi.org/10.1111/j.1365-2788.2004.00617.x

Esbensen, A. J., Mailick, M., \& Krauss, M. W. (2008). Stability and change in health, functional abilities, and behavior problems among adults with and without Down syndrome. American Journal of Mental Retardation, 113(4), 263-277. https://doi.org/10.1352/0895-8017(2008)113[263:SACIHF]2.0.CO;2

Fisher, K. (2004). Health disparities and mental retardation. Journal of Nursing Scholarship, 36(1), 48-53. https://doi.org/10.1111/j.1547-5069.2004.04010.x

Froehlich-Grobe, K., \& Lollar, D. (2011). Obesity and disability: Time to act. American Journal of Preventive Medicine, 41(5), 541-545. https://doi.org/10.1016/j.amepre.2011.07.015

Goldacre, M. J., Wotton, C. J., Seagroatt, V., \& Yeates, D. (2004). Cancers and immune related diseases associated with Down's syndrome: a record linkage study. Archives of Disease in Childhood, 89(11), 1014-1017. https://doi.org/10.1136/adc.2003.046219

Havercamp, S. M., Scandlin, D., \& Roth, M. (2004). Health disparities among adults with developmental disabilities, adults with other disabilities, and adults not reporting disability in North Carolina. Public Health Reports, 119(4), 418. https://doi.org/10.1016/j.phr.2004.05.006

Helfand, M. (2004). Screening for subclinical thyroid dysfunction in nonpregnant adults: a summary of the evidence for the US Preventive Services Task Force. Annals of Internal Medicine, 140(2), 128-141. https://doi.org/10.7326/0003-4819-140-2-200401200-00015

Henderson, A., Lynch, S. A., Wilkinson, S., \& Hunter, M. (2007). Adults with Down's syndrome: the prevalence of complications and health care in the community. The British Journal of General Practice, 57(534), 50-55.

Hill, J. O., \& Melanson, E. L. (1999). Overview of the determinants of overweight and obesity: Current evidence and research issues. Medicine Science Sports Exercise, 11 Suppl, S515-21. https://doi.org/10.1097/00005768-199911001-00005

Janicki, M. P., \& Breitenbach, N. (2000). Aging and Intellectual Disabilities-Improving Longevity and Promoting Health Aging: Summative Report. Geneva: World Health Organization.

Johnson, R. K. (2002). Dietary Intake-How Do We Measure What People Are Really Eating? Obesity Research, 10, 63S-68S. https://doi.org/10.1038/oby.2002.192

Jones, G. C., \& Sinclair, L. B. (2008). Multiple health disparities among minority adults with mobility limitations: An application of the ICF framework and codes. Disability \& Rehabilitation, 30(12-13), 901-915. https://doi.org/10.1080/09638280701800392

Kinne, S., Patrick, D. L., \& Doyle, D. L. (2004). Prevalence of secondary conditions among people with disabilities. American Journal of Public Health, 94(3), 443-445. https://doi.org/10.2105/AJPH.94.3.443

Kirschner, K. L., Breslin, M. L., \& Iezzoni, L. I. (2007). Structural impairments that limit access to health care for patients with disabilities. JAMA: The Journal of the American Medical Association, 297(10), 1121-1125. https://doi.org/10.1001/jama.297.10.1121

Korenberg, J. R., Chen, X. N., Schipper, R., Sun, Z., Gonsky, R., Gerwehr, S., ... Disteche, C. (1994). Down syndrome phenotypes: the consequences of chromosomal imbalance. Proceedings of the National Academy of Sciences, 91(11), 4997-5001. https://doi.org/10.1073/pnas.91.11.4997

Krahn, G. L., Hammond, L., \& Turner, A. (2006). A cascade of disparities: health and health care access for people with intellectual disabilities. Mental Retardation and Developmental Disabilities Research Reviews, 12(1), 70-82. https://doi.org/10.1002/mrdd.20098

Krahn, G., Fox, M. H., Campbell, V. A., Ramon, I., \& Jesien, G. (2010). Developing a health surveillance system for people with intellectual disabilities in the United States. Journal of Policy and Practice in Intellectual Disabilities, 7(3), 155-166. https://doi.org/10.1111/j.17411130.2010.00260.x

Li, C., Ford, E. S., Zhao, G., Croft, J. B., Balluz, L. S., \& Mokdad, A. H. (2010). Prevalence of self-reported clinically diagnosed sleep apnea according to obesity status in men and women: National Health and Nutrition Examination Survey, 2005-2006. Preventive Medicine, 51(1), 18-23. https://doi.org/10.1016/j.ypmed.2010.03.016

Linehan, C., Walsh, P. N., Van Schrojenstein Lantman-de Valk, H., \& Kerr, M., (2004). Pomona: Health Indicators for People with Intellectual Disability. DG Sanco Public Health: European Commission.

Lunsky, Y., Emery, C. F., \& Benson, B. A. (2002). Staff and self-reports of health behaviours, somatic complaints, and 
medications among adults with mild intellectual disability. Journal of Intellectual and Developmental Disability, 27(2), 125-135. https://doi.org/10.1080/13668250220135079-4

Minihan, P. M., Robey, K. L., Long-Bellil, L. M., Graham, C. L., Hahn, J. E., Woodard, L., \& Eddey, G. E. (2011). Desired educational outcomes of disability-related training for generalist physician: Knowledge, attitudes, and skills. Disabilities Medicine Education, 86(9), 1171-1178. https://doi.org/10.1097/ACM.0b013e3182264a25

National Core Indicators. (2012). Using National Core Indicators (NCI) Data for Quality Improvement Initiatives. National Association of State Directors of Developmental Disabilities Services and Human Services Research Institute. Retrieved from http://www.nationalcoreindicators.org

Nelson, D. E., Holtzman, D., Bolen, J., Stanwyck, C. A., \& Mack, K. A. (2000). Reliability and validity of measures from the Behavioral Risk Factor Surveillance System (BRFSS). Social and Preventive Medicine 46, S3-42.

Ouellette - Kuntz, H. (2005). Understanding health disparities and inequities faced by individuals with intellectual disabilities. Journal of Applied Research in Intellectual Disabilities, 18(2), 113-121. https://doi.org/10.1111/j.1468-3148.2005.00240.x

Parker, S. E., Mai, C. T., Canfield, M. A., Rickard, R., Wang, Y., Meyer, R. E., ... Correa, A. (2010). Updated national birth prevalence estimates for selected birth defects in the United States, 2004-2006. Birth Defects Research Part A: Clinical and Molecular Teratology, 88(12), 1008-1016. https://doi.org/10.1002/bdra.20735

Pharr, J. R., \& Bungum, T. (2012). Health disparities experienced by people with disabilities in the United States: A behavioral risk factor surveillance system study. Global Journal of Health Science, 4(6), 99-108. https://doi.org/10.5539/gjhs.v4n6p99

Presson, A. P., Partyka, G., Jensen, K. M., Devine, O. J., Rasmussen, S. A., McCabe, L. L., \& McCabe, E. R. (2013). Current estimate of Down syndrome population prevalence in the United States. The Journal of Pediatrics, 163(4), 1163-1168. https://doi.org/10.1016/j.jpeds.2013.06.013

Pueschel, S. M. (1995). Guidelines for optimal medical care of persons with Down syndrome. Acta Paediatrica, 84(7), 823-827. https://doi.org/10.1111/j.1651-2227.1995.tb13768.x

Reichard, A., Stolzle, H., \& Fox, M. H. (2011). Health disparities among adults with physical disabilities or cognitive limitations compared to individuals with no disabilities in the United States. Disability and Health Journal, 4(2), 59-67. https://doi.org/10.1016/j.dhjo.2010.05.003

Rimmer, J. H., Yamaki, K., Lowry, B. M., Wang, E., \& Vogel, L. C. (2010). Obesity and obesity - related secondary conditions in adolescents with intellectual/developmental disabilities. Journal of Intellectual Disability Research, 54(9), 787-794. https://doi.org/10.1111/j.1365-2788.2010.01305.x

Robertson, J., Emerson, E., Gregory, N., Hatton, C., Turner, S., Kessissoglou, S., \& Hallam, A. (2000). Lifestyle related risk factors for poor health in residential settings for people with intellectual disabilities. Research in Developmental Disabilities, 21(6), 469-486. https://doi.org/10.1016/S0891-4222(00)00053-6

Rubin, S. S., Rimmer, J. H., Chicoine, B., Braddock, D., \& McGuire, D. E. (1998). Overweight prevalence in persons with Down syndrome. Mental Retardation, 36(3), 175-181. https://doi.org/10.1352/0047-6765(1998)036<0175:OPIPWD>2.0.CO;2

Ruddick, L. (2005). Health of people with intellectual disabilities: a review of factors influencing access to health care. British Journal of Health Psychology, 10(4), 559-570. https://doi.org/10.1348/135910705X43769

Scheepers, M., Kerr, M., O'hara, D., Bainbridge, D., Cooper, S. A., Davis, R., ... Wehmeyer, M. (2005). Reducing Health Disparity in People with Intellectual Disabilities: A Report from Health Issues Special Interest Research Group of the International Association for the Scientific Study of Intellectual Disabilities. Journal of Policy and Practice in Intellectual Disabilities, 2(3 - 4), 249-255. https://doi.org/10.1111/j.1741-1130.2005.00037.x

Schopp, L. H., Sanford, T. C., Hagglund, K. J., Gay, J. W., \& Coatney, M. A. (2002). Removing service barriers for women with physical disabilities: promoting accessibility in the gynecologic care setting. Journal of Midwifery \& Women's Health, 47(2), 74-79. https://doi.org/10.1016/S1526-9523(02)00216-7

Schultz, S., Shenkin, J., \& Horowitz, A. (2001). Parental perceptions of unmet dental need and cost barriers to care for developmentally disabled children. Pediatric Dentistry, 23(4), 321-325.

Shin, M., Besser, L. M., Kucik, J. E., Lu, C., Siffel, C., \& Correa, A. (2009). Prevalence of Down syndrome among children and adolescents in 10 regions of the United States. Pediatrics, 124(6), 1565-1571.

https://doi.org/10.1542/peds.2009-0745

Smith, G., \& Ashbaugh, J. (2001). National Core Indicators Project: Phase II consumer survey technical report. Cambridge, MA: Human Services Research Institute. 
Soler, M. A., \& Xandri, G. J. (2011). Nutritional status of intellectual disabled persons with Down syndrome. Nutricion Hospitalaria [online]. 2011, vol.26, n.5, pp. 1059-1066. ISSN 0212-1611.

Stancliffe, R. J., Lakin, K. C., Larson, S. A., Engler, J., Bershadsky, J, Taub, S., Fortune, J., \& Ticka, R. (2011). Overweight and Obesity Among Adults With Intellectual Disabilities Who Use Intellectual Disability/Developmental Disability Services in 20 U.S. States. American Journal on Intellectual and Developmental Disabilities: November 2011, Vol. 116, No. 6, pp. 401-418. https://doi.org/10.1352/1944-7558-116.6.401

Stancliffe, R. J., Lakin, K. C., Larson, S. A., Engler, J., Taub, S., Fortune, J., \& Bershadsky, J. (2012). Demographic Characteristics, Health Conditions, and Residential Service Use in Adults with Down Syndrome in 25 US States. Intellectual and Developmental Disabilities, 50(2), 92-108. https://doi.org/10.1352/1934-9556-50.2.92

Sutherland, G., Couch, M. A., \& Iacono, T. (2002). Health issues for adults with developmental disability. Research in Developmental Disabilities, 23(6), 422-445. https://doi.org/10.1016/j.phr.2004.05.006

Trois, M. S., Capone, G. T., Lutz, J. A., Melendres, M. C., Schwartz, A. R., Collop, N. A., \& Marcus, C. L. (2009). Obstructive sleep apnea in adults with Down syndrome. Journal of Clinical Sleep Medicine, 5(4), 317-323.

U.S. Department of Health and Human Services (2008). Physical Activity Guidelines Advisory Committee Report. Washington, DC.

United States Department of Health and Human Services (2011). Healthy People 2020. Retrieved from http://www.healthypeople.gov/2020

United States Public Health Service. (2002). Closing the Gap: A National Blueprint for Improving the Health of Individuals with Mental Retardation. Washington, DC: U.S. Government Printing Office.

US Department of Health and Human Services (2001) The surgeon general's call to action to prevent and decrease overweight and obesity. Washington, DC: US Government Printing Office.

van Allen, M. I., Fung, J., \& Jurenka, S. B. (1999). Health care concerns and recommended clinical practice document for adults with Down syndrome. American Journal of Medical Genetics, 89(2), 100-110. https://doi.org/10.1002/(SICI)1096-8628(19990625)89:2<100::AID-AJMG8>3.0.CO;2-N

Voelker, R. (2002). Improved care for neglected population must be "rule rather than exception". Journal of the American Medical Association, 288(3), 299-301. https://doi.org/10.1001/jama.288.3.299

Waldman, H. B., \& Perlman, S. P. (2002). Preparing to meet the dental needs of individuals with disabilities. Journal of Dental Education, 66(1), 82-85.

Walsh, P. N., Kerr, M., \& van Schrojenstein Lantman-de Valk, H. M. J. (2003). Health indicators for people with intellectual disabilities: A European perspective. The European Journal of Public Health, 13(1), 47-50. https://doi.org/10.1093/eurpub/13.suppl_1.47

Wechsler, J., Greene, M., McDevitt, M. A., Anastasi, J., Karp, J. E., Le Beau, M. M., \& Crispino, J. D. (2002). Acquired mutations in GATA1 in the megakaryoblastic leukemia of Down syndrome. Nature Genetics, 32(1), 148-152. https://doi.org/10.1038/ng955

Whitehead, M. (1992). The concepts and principles of equity and health. International Journal of Health Services, 22(3), 429-445. https://doi.org/10.2190/986L-LHQ6-2VTE-YRRN

Wilkinson, J. E., Lauer, E., Freund, K. M., \& Rosen, A. K. (2011). Determinants of mammography in women with intellectual disabilities. The Journal of the American Board of Family Medicine, 24(6), 693-703. https://doi.org/10.3122/jabfm.2011.06.110095

Wisdom, J. P., McGee, M. G., Horner-Johnson, W., Michael, Y. L., Adams, E., \& Berlin, M. (2010). Health disparities between women with and without disabilities: A review of the research. Social Work in Public Health, 25(3), 368-386. https://doi.org/10.1080/19371910903240969

World Cancer Research Fund / American Institute for Cancer Research. (2007). Determinants of weight gain, overweight, and obesity. In Food, Nutrition, Physical Activity, and the Prevention of Cancer: a Global Perspective. Washington DC: AICR.

\section{Copyrights}

Copyright for this article is retained by the author(s), with first publication rights granted to the journal.

This is an open-access article distributed under the terms and conditions of the Creative Commons Attribution license which permits unrestricted use, distribution, and reproduction in any medium, provided the original work is properly cited. 